\title{
A Close Look at Model-Dependent Monetary Policy Design
}

Miguel Casares

\begin{abstract}
This article first explores the implications of model specification on the design of targeting rules in a world of model certainty. As a general prescription, a targeting rule must counterbalance the private-sector dynamics: The more backward-looking behavior is observed in either the output gap or inflation, the more forward-looking monetary policy should be. Likewise, a more forwardlooking economy would require stronger backward-looking reactions of the nominal interest rate to the output gap or inflation. The article also analyzes the effects of implementing monetary policy in an environment with uncertainty. Our results indicate that a simple model-invariant rule of the style proposed by Taylor (1993) performs better than a model-dependent targeting rule in the presence of moderate parameter uncertainty. (JEL E52)
\end{abstract}

Federal Reserve Bank of St. Louis Review, September/October 2006, 88(5), pp. 451-69.

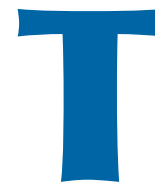

he introduction of the so-called targeting rules in articles such as Svensson (1999) and Clarida, Galí, and Gertler (1999) represented a keystone for monetary policy analysis. A targeting rule is obtained by solving a central-bank optimization program that includes both an objective (loss) function and a single model describing the economy. Therefore, targeting rules have two major characteristics for monetary policy: They represent first-order optimality conditions for the central bank, and they rely on the particular model used to describe macroeconomic fluctuations. Targeting rules have probably received so much attention because of their first characteristic: They entail an optimal behavior for the central bank. The optimality property brought about insightful discussions on the convenience of a commitment-type decision process (see Clarida, Galí, and Gertler, 1999;

Woodford, 1999; and Svensson, 2002). This article focuses on the second characteristic of targeting rules-their dependence on a particular model specification.

Two building blocks are required to define a targeting rule: a macro model and an objective (loss) function for the central bank. The model of this article consists of two equations representing the aggregate demand and aggregate supply behavior. It is a semi-structural model that allows for both backward-looking and forward-looking dynamics on inflation and the output gap while retaining much of the flavor of the New Keynesian model. ${ }^{1}$ As for the central-bank loss function, it implies that monetary policy targets the volatilities of inflation, the output gap, and the nominal interest rate. This loss function is not directly obtained from any welfare criterion and simply represents the task of macro stabilization frequently assigned to central banks. A fully fledged (New Keynesian) model should be introduced to calculate its

1 See Christiano, Eichenbaum, and Evans (2005) for a New Keynesian large model that incorporates backward-looking features.

\footnotetext{
Miguel Casares is an assistant professor at the Departamento de Economía, Universidad Pública de Navarra, Pamplona, Spain. The author thanks Edward Nelson, James Bullard, Bennett T. McCallum, William Gavin, Yi Wen, and Riccardo DiCecio for insightful comments and suggestions. This article was written while the author was a visiting scholar at the Federal Reserve Bank of St. Louis, which he thanks for its hospitality; he also thanks the Spanish Ministry of Education and Science for financial support.

(C) 2006, The Federal Reserve Bank of St. Louis. Articles may be reprinted, reproduced, published, distributed, displayed, and transmitted in their entirety if copyright notice, author name(s), and full citation are included. Abstracts, synopses, and other derivative works may be made only with prior written permission of the Federal Reserve Bank of St. Louis.
} 
welfare-theoretic targeting rule, which unfortunately goes beyond the scope of this article. ${ }^{2}$

The analysis will be executed in three steps. In the next section, the targeting rule is derived and, after some algebra, presented as an interest rate optimal reaction function. This optimized interest rate rule provides response coefficients of the nominal interest rate to its own lags or leads and to other key variables such as inflation or the output gap. In the second step, in the following section, a baseline calibration is proposed, borrowing estimates from the New Keynesian literature. In turn, the calibrated model is able to replicate many regularities observed in second-moment statistics from actual data. Finally, the third step consists of looking at how the optimal response coefficients change when the model parameters vary.

As one alternative to targeting rules, the famous Taylor rule (Taylor, 1993) is an example of model-invariant monetary policy design. The Taylor rule is a simple rule (also called instrument rule) characterized by general policy prescriptions: The nominal interest rate should be raised (lowered) when inflation is above (below) its target value, when output is above (below) its potential level, or when the previous nominal interest is above (below) its target value. Thus, it can be said that a Taylor rule is a model-invariant policy rule because its formulation is not based on any specific model. In spite of being suboptimal, modelinvariant rules have one advantage over targeting rules: Their stabilizing performance is more robust to model changes than model-dependent targeting rules (Levin and Williams, 2003).

The final section of this article studies the convenience of using a model-independent rule when there is uncertainty surrounding the true value of the model parameters. The presence of uncertainty may discourage the implementation of a targeting rule in favor of a model-independent rule. Some examples of parameter misidentification will recommend that the central bank choose

\footnotetext{
2 Woodford (2003a) shows the welfare-theoretic loss functions implied by various specifications of the New Keynesian model. Moreover, Levin et al. (2006) and Casares (2006), respectively, characterize a welfare-theoretic targeting rule using a New Keynesian model for the United States and the euro area.
}

a model-invariant rule (a Taylor-type rule) for its better stabilizing performance.

\section{TARGETING RULES}

As mentioned in the introduction, a targeting rule is built on two blocks: the model that represents the economic behavior of the private sector and the central-bank loss function that incorporates the objectives (or targets) of monetary policy. Regarding the model, the following aggregate demand-aggregate supply, (AD)-(AS), pair of equations determine the dynamic behavior of the output gap $\left(y_{t}\right)$ and inflation $\left(\pi_{t}\right)$ :

(AD)

$$
\begin{aligned}
& y_{t}=\theta_{0} y_{t-1}+\left(1-\theta_{0}\right) E_{t} y_{t+1}-\theta_{1}\left(R_{t}-E_{t} \pi_{t+1}\right)+v_{t}, \\
& \text { (AS) } \pi_{t}=\phi_{0} \pi_{t-1}+\left(1-\phi_{0}\right) E_{t} \pi_{t+1}+\phi_{1} y_{t}+\varepsilon_{t}
\end{aligned}
$$

where $0.0 \leq \theta_{0} ; \phi_{0} \leq 1.0 ; \theta_{1}, \phi_{1}>0.0 ; R_{t}$ is the nominal interest rate; and both $v_{t}$ and $\varepsilon_{t}$ are whitenoise shocks with constant standard deviations, $\sigma_{v}$ and $\sigma_{\varepsilon}$. Note that $E_{t}$ denotes the rational expectations operator conditional to information available in period $t$. The output gap, $y_{t}$, is defined by the fractional difference between current output and potential output. ${ }^{3}$ This (AD)-(AS) model has been recently used in work such as Smets (2003), Moreno (2004), Lindé (2005), and Moessner (2005). The AD curve negatively relates fluctuations of the output gap to the real interest rate in a way that conveys both backward-looking and forward-looking behavior. External habit formation in households' utility function can explain the introduction of the backward-looking term $y_{t-1}$ as first pointed out by Fuhrer (2000). Meanwhile, the rate of inflation evolves in accordance with the AS curve, which may represent the presence of staggered price contracts as in Fuhrer and Moore (1995). Alternatively, the AS curve is similar to the inflation equation obtained when extending the sticky-price model described by Calvo (1983) to allow price indexation of nonoptimal prices on the previous observation of inflation as in Christiano, Eichenbaum, and Evans (2005). The

\footnotetext{
3 The model abstracts from the way potential output is calculated because it is not relevant for the purposes of this article.
} 
selection of this model can be justified on the following basis:

- Simple model: Two dynamic equations representing $\mathrm{AD}$ and $\mathrm{AS}$ behavior. The simplicity of the model will permit us to write the targeting rule as an interest-rate reaction function.

- Semi-structural equations: The pair (AD)-(AS) shows a number of similarities to the behavioral equations obtained in a closed-economy New Keynesian model with consumption external habit formation, Calvo-style sticky prices, and price indexation on lagged inflation as pointed out by Smets (2003) and Moreno (2004). However, it must be recognized that it does not accurately represent any particular microfounded economy. ${ }^{4}$

- The pair (AD)-(AS) collects a broad variety of model specifications. The values for $\theta_{0}$ and $\phi_{0}$ ranging from 0.0 to 1.0 can reproduce from purely backward-looking to completely forward-looking dynamics for the output gap and inflation (and all the cases in between). Thus, the fully forward-looking New Keynesian economy is depicted by the case $\theta_{0}=\phi_{0}=0.0$, which has been used in articles such as Clarida, Galí, and Gertler (1999), McCallum (2003), Woodford (2003b), and Preston (2006). The purely backward-looking model $\left(\theta_{0}=\phi_{0}=1.0\right)$ is less frequently found in the literature (e.g., see Söderström, 2002, and Svensson, 2003). ${ }^{5}$

Turning to the second building block for a targeting rule, let us suppose that the central bank pursues a monetary policy that aims at reducing variability of inflation, the output gap, and the nominal interest rate. This is a common assumption in the literature on monetary policy rules

4 In addition, the stochastic terms appearing in (AD) and (AS) have no direct link to structural shocks.

5 One notices that the backward-looking (AD)-(AS) case can also be interpreted as a vector autoregression (VAR)-type representation of the economy and therefore can relate it to the literature on structural VAR models. See, e.g., Galí (1992) and Christiano, Eichenbaum, and Evans (2005).
(Smets, 2003; Giannoni and Woodford, 2003; Woodford, 2003b; and Moessner, 2005) and may be considered a realistic ad hoc way of introducing the central bank's stabilizing preference. Neglecting constant terms (or setting them to zero), the loss function for the central bank in period $t$ is therefore

$$
L_{t}=\pi_{t}^{2}+\gamma_{y} y_{t}^{2}+\gamma_{R} R_{t}^{2},
$$

with $\gamma_{Y}$ and $\gamma_{R}$ being nonnegative values that define the relative weights on the central bank's stabilizing preference.

The targeting rule is going to be derived using the timeless perspective approach defined by Woodford (1999, p. 18) and, in a more formal manner, in Woodford (2003a, pp. 538-39). The timeless perspective implies that the first-order conditions of the central bank do not depend on the moment of time in which they are set. In other words, they do not change over time and the central bank's behavior is time consistent. Regarding its practical calculation, the timeless perspective commitment is obtained by considering that the macro relationships involved in the model hold in all the periods (past, current, and future). This makes the timing of the decision irrelevant.

Accordingly, the optimal monetary policy is then designed by minimizing

$$
\sum_{j=0}^{\infty} \beta^{j} E_{t} L_{t+j}
$$

where $\beta<1.0$ is the discount factor, subject to (AD)-(AS) relationships in periods $t+j$ with $j \in(\ldots,-2,-1,0,1,2, \ldots)$. The first-order conditions that result from such a central-bank optimizing program are

(TR.1)

$$
2 \pi_{t}-\beta^{-1} \theta_{1} \lambda_{t-1}+\xi_{t}-\beta \phi_{0} E_{t} \xi_{t+1}-\left(1-\phi_{0}\right) \beta^{-1} \xi_{t-1}=0,
$$

(TR.2)

$$
2 \gamma_{y} y_{t}+\lambda_{t}-\beta \theta_{0} E_{t} \lambda_{t+1}-\beta^{-1}\left(1-\theta_{0}\right) \lambda_{t-1}-\phi_{1} \xi_{t}=0,
$$

$$
2 \gamma_{R} R_{t}+\theta_{1} \lambda_{t}=0
$$

where $\lambda_{t}$ and $\xi_{t}$ are the Lagrange multipliers associated with (AD) and (AS), respectively. Now we will make substitutions in (TR.1)-(TR.3) 
to eliminate the Lagrange multipliers. After the algebra,

$$
\begin{aligned}
\pi_{t}= & \frac{\beta^{-2} \gamma_{R}\left(1-\phi_{0}\right)\left(1-\theta_{0}\right)}{\phi_{1} \theta_{1}} R_{t-2}-\frac{\beta^{-1} \gamma_{R}\left(\phi_{1} \theta_{1}+\left(1-\phi_{0}\right)+\left(1-\theta_{0}\right)\right)}{\phi_{1} \theta_{1}} R_{t-1} \\
& +\frac{\gamma_{R}\left(1+\phi_{0}\left(1-\theta_{0}\right)\right)}{\phi_{1} \theta_{1}} R_{t}+\frac{\gamma_{R} \theta_{0}\left(1-\phi_{0}\right)}{\phi_{1} \theta_{1}} E_{t-1} R_{t}-\frac{\beta \gamma_{R}\left(\phi_{0}+\theta_{0}\right)}{\phi_{1} \theta_{1}} E_{t} R_{t+1} \\
& +\frac{\beta^{2} \gamma_{R} \phi_{0} \theta_{0}}{\phi_{1} \theta_{1}} E_{t} R_{t+2}+\frac{\beta^{-1} \gamma_{y}\left(1-\phi_{0}\right)}{\phi_{1}} y_{t-1}-\frac{\gamma_{y}}{\phi_{1}} y_{t}+\frac{\beta \gamma_{y} \phi_{0}}{\phi_{1}} E_{t} y_{t+1} .
\end{aligned}
$$

The above expression can be rearranged so as to reach the following optimal reaction function of the central bank in terms of the nominal interest rate:

(TR)

$$
\begin{aligned}
R_{t} & =\mu_{1} R_{t-2}+\mu_{2} R_{t-1}+\mu_{3} E_{t-1} R_{t}+\mu_{4} E_{t} R_{t+1} \\
& +\mu_{5} E_{t} R_{t+2}+\mu_{6} \pi_{t}+\mu_{7} y_{t-1}+\mu_{8} y_{t}+\mu_{9} E_{t} y_{t+1},
\end{aligned}
$$

where $\mu_{1}=-\frac{\beta^{-2}\left(1-\phi_{0}\right)\left(1-\theta_{0}\right)}{1+\phi_{0}\left(1-\theta_{0}\right)}$,

$\mu_{2}=\frac{\beta^{-1}\left(\phi_{1} \theta_{1}+\left(1-\phi_{0}\right)+\left(1-\theta_{0}\right)\right)}{1+\phi_{0}\left(1-\theta_{0}\right)}, \mu_{3}=-\frac{\left(1-\phi_{0}\right) \theta_{0}}{1+\phi_{0}\left(1-\theta_{0}\right)}$,

$\mu_{4}=\frac{\beta\left(\phi_{0}+\theta_{0}\right)}{1+\phi_{0}\left(1-\theta_{0}\right)}, \mu_{5}=-\frac{\beta^{2} \phi_{0} \theta_{0}}{1+\phi_{0}\left(1-\theta_{0}\right)}$,

$\mu_{6}=\frac{\phi_{1} \theta_{1}}{\gamma_{R}\left(1+\phi_{0}\left(1-\theta_{0}\right)\right)}, \mu_{7}=-\frac{\beta^{-1} \gamma_{y}\left(1-\phi_{0}\right) \theta_{1}}{\gamma_{R}\left(1+\phi_{0}\left(1-\theta_{0}\right)\right)}$,

$\mu_{8}=\frac{\gamma_{y} \theta_{1}}{\gamma_{R}\left(1+\phi_{0}\left(1-\theta_{0}\right)\right)}$, and $\mu_{9}=-\frac{\beta \gamma_{y} \phi_{0} \theta_{1}}{\gamma_{R}\left(1+\phi_{0}\left(1-\theta_{0}\right)\right)}$.

The derivation of (TR) represents a bridge between targeting rules and instrument rules that could help to close the gap opened by Svensson (2003). ${ }^{6}$ It is easy to notice that (TR) recalls the instrument-style of a Taylor rule with similar prescriptions: The nominal interest rate must respond positively to current deviations of inflation from target $\left(\mu_{6}>0.0\right)$ and to the current output gap $\left(\mu_{8}>0.0\right)$. In some sense, (TR) can also be considered an instrument rule because it provides an operational reaction function for the central bank as advocated by McCallum (1999). ${ }^{7}$ Besides, (TR) does not include any direct reaction to

6 See McCallum and Nelson (2005) and Svensson (2005) for further insightful discussions on the use of targeting rules versus instrument rules.

7 Assuming that the output gap were observable. shocks, which makes it robust to any assumption on their generating process. ${ }^{8}$ Nevertheless, it looks much more complex than a Taylor-type rule with regard to the internal dynamic structure. There are two lags $\left(R_{t-2}\right.$ and $\left.R_{t-1}\right)$, two leads $\left(E_{t} R_{t+1}\right.$ and $E_{t} R_{t+2}$ ), and the expected value of the current interest rate computed in the past period $\left(E_{t-1} R_{t}\right)$. Moreover, one lag and one lead of the output gap $\left(y_{t-1}\right.$ and $\left.E_{t} y_{t+1}\right)$ also appear in (TR).

Accordingly, (TR) implies that optimal monetary policy must combine backward-looking and forward-looking dynamics for the nominal interest rate. This represents a more general case than the optimal instrument-style rule derived by Giannoni and Woodford (2003) in a forward-looking model, which included only backward-looking terms.

Note that the backward-looking parameters from the (AD)-(AS) equations, $\theta_{0}$ and $\phi_{0}$, take part in the determination of all the optimal $\mu$ 's reaction coefficients for the targeting rule (TR). Therefore the degree of backward-looking behavior in the dynamics of either the output gap or inflation is key for the optimal design of monetary policy. This point will be further investigated here in future sections.

Finally, the influence of the central bank's policy parameters, $\gamma_{y}$ and $\gamma_{R}$, in the design of (TR) is found only in the size of the responses of the nominal interest rate to the output gap terms (both parameters) and to inflation (only $\gamma_{R}$ ). In other words, the value of either $\gamma_{y}$ or $\gamma_{R}$ is irrelevant for the determination of the coefficients on the lags and leads of $R_{t}$ in (TR). These coefficients (from $\mu_{1}$ to $\mu_{5}$ ) are completely determined by the parameters that appear in the (AD)-(AS) equations, plus $\beta$.

\section{BASELINE CALIBRATION}

A baseline calibration is required to establish a benchmark reference for the analysis conducted below. The calibration procedure taken is simple: Choose some arbitrary values borrowed from the underlying micro structure of the New Keynesian model and check their empirical fit. However, the calibration is not intended to match data from any

${ }^{8}$ Giannoni and Woodford (2002) support the use of targeting rules because they are independent from the nature of the model's shocks. 
particular economy. We will show just that the empirical properties of the model may resemble second-moment statistics observed in actual data.

Table 1 displays the numerical values of the baseline calibration. Both the (AD) and (AS) curves evenly feature backward- and forward-looking dynamics $\left(\theta_{0}=\phi_{0}=0.5\right)$. The (AD) curve with $\theta_{0}=0.5$ corresponds to a New Keynesian economy featuring strong habit formation on households' consumption preferences as advocated by Fuhrer (2000). ${ }^{9}$ Likewise, having $\phi_{0}=0.5$ in the (AS) equation implies that there is full indexation of nonoptimal prices to lagged inflation as estimated in Woodford (2003a, Chap. 5) or Christiano, Eichenbaum, and Evans (2005). Remarkably, the equal-weight calibration used here is consistent with the numerical estimates reported by Smets (2003) using euro area data and by Moreno (2004) for the U.S. economy. ${ }^{10}$

Regarding the slope coefficients, we set $\theta_{1}=0.06$ in the (AD) curve while $\phi_{1}=0.01$ in the (AS) curve. The value for the (AD) slope is found in a New Keynesian model with a habit-formation coefficient equal to 0.8 and a relative risk aversion coefficient for consumption in the utility function equal to 2.0. The calibrated (AS) slope, $\phi_{1}=0.01$, is very close to the slope of the hybrid New Keynesian Phillips curve from a sticky-price model à la Calvo, where firms adjust prices optimally once per year on average and index them to lagged inflation in periods without optimal adjustment. ${ }^{11}$

The model was solved with two alternative monetary policy rules: the optimal (TR) derived above and the Taylor-type rule with interest-rate smoothing ${ }^{12}$ :

\footnotetext{
9 As the external habit-formation coefficient approaches 1.0, the New Keynesian model delivers an (AD) curve with $\theta_{0}=0.5$.

${ }^{10}$ Nevertheless, the degree of backward-lookingness of U.S. inflation has been subject to controversy. Galí and Gertler (1999) claim that inflation responds strongly to future developments $\left(\phi_{0}<0.5\right)$, while Lindé (2005) finds the opposite result $\left(\phi_{0}>0.5\right)$.

${ }^{11}$ Under the common assumption of constant capital, the slope of the Phillips curve also depends on the Dixit-Stiglitz elasticity and the elasticity of the real marginal costs with respect to output. Our choice of $\phi_{1}=0.01$ is obtained when the former is 6 and the latter is 0.56, as in Amato and Laubach (2003), Woodford (2003a, Chap. 5), and Christiano, Eichenbaum, and Evans (2005).

${ }^{12}$ The output gap coefficient must be divided by 4 to assimilate Taylor
} (1993) coefficients because they were proposed for a rule based

\section{Table 1}

\section{Baseline Calibration}

$\begin{array}{llll}\text { AD curve } & \theta_{0}=0.5 & \theta_{1}=0.06 & \sigma_{v}=0.6 \\ \text { AS curve } & \phi_{0}=0.5 & \phi_{1}=0.01 & \sigma_{\varepsilon}=0.2 \\ \text { TayR } & \mu_{\pi}=1.5 & \mu_{y}=0.5 & \mu_{R}=0.80 \\ \text { TR } & \gamma_{y}=0.04 & \gamma_{R}=0.30 & \beta=0.99\end{array}$

(TayR) $R_{t}=\left(1-\mu_{R}\right)\left[\mu_{\pi} \pi_{t}+\frac{\mu_{y}}{4} y_{t}\right]+\mu_{R} R_{t-1}$,

with the original numbers proposed in Taylor (1993), $\mu_{\pi}=1.5$ and $\mu_{y}=0.5$ together with a significant degree of interest-rate smoothing, $\mu_{R}=0.80$. Regarding the calibration of (TR), the $\mu$ 's coefficients depend on the values already assigned to $\theta_{0}, \theta_{1}, \phi_{0}$, and $\phi_{1}$ plus on the central bank parameters, $\beta, \gamma_{y}$, and $\gamma_{R}$. The discount factor takes the standard value $\beta=0.99$, which implies a 4 percent annualized rate of discount. For the parameters on the central-bank stabilizing preference, we set $\gamma_{y}=0.04$ and $\gamma_{R}=0.30$, which reflects a monetary policy that is more concerned with stabilizing inflation than the output gap or the nominal interest rate. ${ }^{13}$

The (percent) standard deviations of the stochastic disturbances are $\sigma_{v}=0.6$ and $\sigma_{\varepsilon}=0.2$ because they let the model have realistic volatilities in the output gap, inflation, and the nominal interest rate. Table 2 gives a comparison between some second-moment statistics obtained in our calibrated model under both (TR) and (TayR) and numbers obtained for the United States, the euro area, the United Kingdom, and Japan. ${ }^{14}$ Four

\footnotetext{
on annual observations, whereas our model provides quarterly observations.

13 These loss function weights are similar to those used by Giannoni and Woodford (2003).

${ }^{14}$ The data are quarterly observations for the United States, the euro area, the United Kingdom, and Japan during the period 1980:Q12004:Q4. The rate of inflation is the annualized growth rate of the GDP deflator from the previous quarter except for the case of the United Kingdom, which is the annualized growth rate of the retail price index. The output gap has been computed by taking off a linear trend from the logarithm of the real GDP except for the case of Japan, which was obtained from a quadratic detrending due to its structural break on long-run growth. The nominal interest rate is the annualized rate of return on a comparable short-run risk-free bond. (Source:
} 
Table 2

Business Cycle Statistics: Baseline Calibrated Model vs. Data

\begin{tabular}{|c|c|c|c|c|c|c|}
\hline & $\begin{array}{l}\text { Model with } \\
\text { (TayR) }\end{array}$ & $\begin{array}{l}\text { Model with } \\
\text { (TR) }\end{array}$ & United States & Euro area & United Kingdom & Japan \\
\hline \multicolumn{7}{|c|}{ Standard deviations (annualized, \%) } \\
\hline$\pi$ & 2.88 & 2.36 & 1.98 & 2.78 & 3.63 & 2.58 \\
\hline$y$ & 2.21 & 1.92 & 2.05 & 1.75 & 2.28 & 2.88 \\
\hline$R$ & 3.29 & 3.12 & 3.07 & 3.62 & 3.38 & 3.15 \\
\hline \multicolumn{7}{|c|}{ Coefficients of correlation } \\
\hline$(y, \pi)$ & 0.38 & 0.19 & 0.04 & 0.04 & 0.20 & 0.28 \\
\hline$(y, R)$ & 0.20 & -0.04 & 0.11 & 0.24 & 0.28 & 0.31 \\
\hline$(\pi, R)$ & 0.80 & 0.35 & 0.78 & 0.88 & 0.84 & 0.77 \\
\hline \multicolumn{7}{|c|}{ Coefficients of autocorrelation } \\
\hline$\pi$ & 0.86 & 0.83 & 0.93 & 0.95 & 0.94 & 0.54 \\
\hline$y$ & 0.86 & 0.80 & 0.92 & 0.95 & 0.94 & 0.95 \\
\hline$R$ & 0.97 & 0.97 & 0.97 & 0.98 & 0.98 & 0.97 \\
\hline
\end{tabular}

business cycle regularities can be extracted from observing the columns of actual data:

- The variabilities of the rate of inflation, the output gap, and the nominal interest rate are not very different. Their annualized standard deviations mostly are between 2 percent and 3 percent. The nominal interest rate seems to have a higher standard deviation relative to the other two variables.

- There is a weakly positive correlation between the output gap and either inflation or the nominal interest rate.

- There is a strongly positive correlation between the rate of inflation and the nominal interest rate.

- The three variables have high coefficients of autocorrelation.

As documented in Table 2, the calibrated model with (TayR) provides second-moment statistics that never deviate significantly from the numbers obtained in the data. It could be said that it correctly replicates the data regularities that we

International Financial Statistics, August 2005, International Monetary Fund, except for U.K. real GDP and inflation, which were obtained from the National Statistics Office of the U.K. government, available at www.statistics.gov.uk.) just mentioned. The calibrated model with the optimal rule (TR) provides statistics of similar magnitude to the data in many cases, although it does not reproduce correctly two of the correlations found in the data. The nominal interest rate has a slightly negative coefficient of correlation with output (slightly positive in the data) and also quite a low positive correlation with the rate of inflation (strongly positive correlation in the data). Table 2 also shows that the performance of the calibrated (TayR) is not dramatically worse than the performance under the calibrated optimal policy (TR). The higher standard deviations of the target variables when applying (TayR) are between 5 and 22 percent higher than those obtained when using (TR).

\section{SENSITIVITY ANALYSIS IN A WELL-SPECIFIED MODEL...}

This section addresses the implications of alternative specifications of the four (AD)-(AS) model parameters $\left(\theta_{0}, \theta_{1}, \phi_{0}\right.$, and $\left.\phi_{1}\right)$ and the centralbank policy weights $\left(\gamma_{y}\right.$ and $\left.\gamma_{R}\right)$. In particular, we will examine how a change in each parameter from the baseline calibration reshapes the $\mu$ 's coefficients on the optimal policy rule (TR).

Let us start by discussing the consequences 


\section{Figure 1}

\section{Coefficients of the Targeting Rule (TR) Depending on the Backward-Looking Parameters of the (AD) Equation, $\theta_{0}$, and the (AS) Equation, $\phi_{0}$}
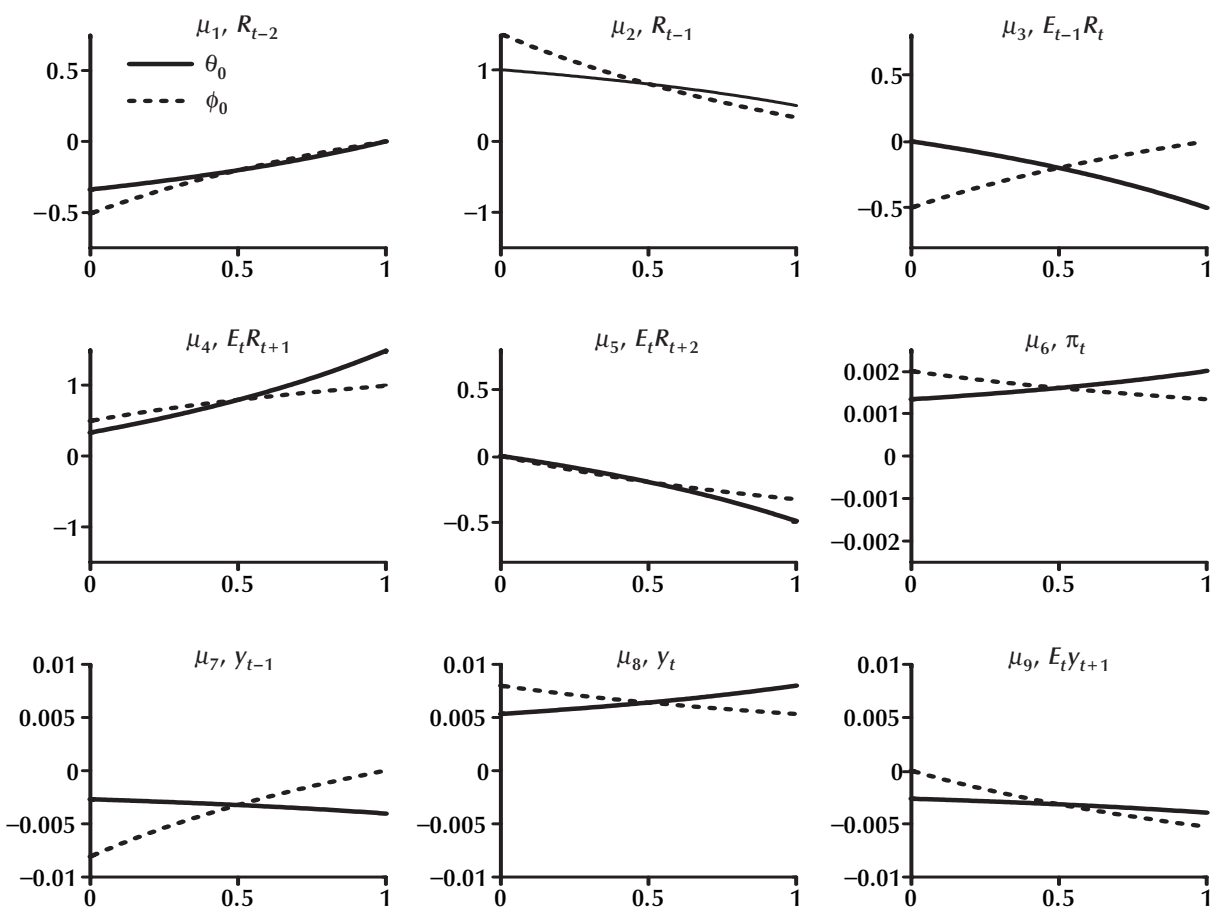

of altering the backward-looking coefficients, $\theta_{0}$ and $\phi_{0}$, from their lower bound (0.0) to their upper bound (1.0). Results are plotted in Figure 1. The solid lines of Figure 1 show the impact of changing the degree of backward-looking behavior on the output gap $\left(\theta_{0}\right)$, whereas the dotted lines represent the influence when increasing the backwardlooking pattern of inflation $\left(\phi_{0}\right)$. The intersection of the two lines provides the optimal coefficients under the baseline calibration at $\theta_{0}=\phi_{0}=0.5$.

As displayed in Figure 1, the degree of backward-lookingness of both the output gap and inflation plays a crucial role on the design of the targeting rule. Any change in either $\theta_{0}$ or $\phi_{0}$ affects all the nine $\mu$ 's coefficients that enter (TR). Furthermore, both $\theta_{0}$ and $\phi_{0}$ shape the internal dynamics of (TR) in a similar way. Thus, an increase in either $\theta_{0}$ or $\phi_{0}$ would lead to a decrease in the coefficients on lagged nominal interest rates $\left(\mu_{1}\right.$ and $\left.\mu_{2}\right)$ and, also, an increase in the coefficients on future nominal interest rates $\left(\mu_{4}\right.$ and $\left.\mu_{5}\right)$. The latter assessment must be understood in terms of the absolute value of the coefficients because both $\mu_{1}$ and $\mu_{5}$ are negative coefficients.

Thus, there is a well-marked link between the model structure and optimal monetary policy: A more backward-looking economy requires a more forward-looking monetary policy rule. In a symmetric manner, an economy with deep forward-looking dynamics should have persistent inertia in the implementation of monetary policy. Remarkably, this "counterbalance assignment" is applicable to the internal structure of either the output gap or inflation. This finding represents a significant extension of a similar result reported by Leitemo (2006) restricted to the relationship between optimal policy and inflation dynamics. ${ }^{15}$

${ }^{15}$ As another difference from Leitemo (2006), our central bank loss function is also more general because it incorporates interest-rate targeting. 
Table 3

Targeting Rule Coefficients under Alternative Model Specifications for $\theta_{0}$ and $\phi_{0}$

\begin{tabular}{|c|c|c|c|c|c|c|c|c|c|}
\hline & $\mu_{1}$ & $\mu_{2}$ & $\mu_{3}$ & $\mu_{4}$ & $\mu_{5}$ & $\mu_{6}$ & $\mu_{7}$ & $\mu_{8}$ & $\mu_{9}$ \\
\hline $\begin{array}{l}\text { Baseline } \\
\left(\theta_{0}=0.5, \phi_{0}=0.5\right)\end{array}$ & -0.20 & 0.81 & -0.20 & 0.79 & -0.20 & 0.0016 & -0.0032 & 0.0064 & -0.0032 \\
\hline $\begin{array}{l}\text { Forward-looking output gap } \\
\left(\theta_{0}=0.0, \phi_{0}=0.5\right)\end{array}$ & -0.34 & 1.01 & 0.0 & 0.33 & 0.0 & 0.0013 & -0.0027 & 0.0053 & -0.0026 \\
\hline $\begin{array}{l}\text { Forward-looking inflation } \\
\left(\theta_{0}=0.5, \phi_{0}=0.0\right)\end{array}$ & -0.51 & 1.52 & -0.50 & 0.49 & 0.0 & 0.0020 & -0.0081 & 0.0080 & 0.0 \\
\hline $\begin{array}{l}\text { Purely forward-looking } \\
\left(\theta_{0}=0.0, \phi_{0}=0.0\right)\end{array}$ & -1.02 & 2.02 & 0.0 & 0.0 & 0.0 & 0.0020 & -0.0081 & 0.0080 & 0.0 \\
\hline $\begin{array}{l}\text { Backward-looking output gap } \\
\left(\theta_{0}=1.0, \phi_{0}=0.5\right)\end{array}$ & 0.0 & 0.51 & -0.50 & 1.49 & -0.49 & 0.0020 & -0.0040 & 0.0080 & -0.0040 \\
\hline $\begin{array}{l}\text { Backward-looking inflation } \\
\left(\theta_{0}=0.5, \phi_{0}=1.0\right)\end{array}$ & 0.0 & 0.34 & 0.0 & 0.99 & -0.33 & 0.0013 & 0.0 & 0.0053 & -0.0053 \\
\hline $\begin{array}{l}\text { Purely backward-looking } \\
\left(\theta_{0}=1.0, \phi_{0}=1.0\right)\end{array}$ & 0.0 & 0.0006 & 0.0 & 1.98 & -0.98 & 0.0020 & 0.0 & 0.0080 & -0.0079 \\
\hline
\end{tabular}

For illustrative purposes, Table 3 contains the values of the (TR) coefficients for alternative specifications of both $\theta_{0}$ and $\phi_{0}$. The purely forwardlooking economy $\left(\theta_{0}=\phi_{0}=0.0\right)$ would have the highest lagged nominal interest rate coefficients $\left(\mu_{1}=-1.02\right.$ and $\left.\mu_{2}=2.02\right)$ and no reaction to the expected future nominal interest rates $\left(\mu_{4}=\mu_{5}=\right.$ $0.0)$. By contrast, a purely backward-looking economy $\left(\theta_{0}=\phi_{0}=1.0\right)$ would have an optimal policy with strong reactions to expected future developments ( $\mu_{4}=1.98$ and $\mu_{5}=-0.98$ ) and practically no dependence on past movements $\left(\mu_{1}=0.0\right.$ and $\mu_{2} \simeq 0.0$ ).

Figure 1 and Table 3 also inform about the impact of changing either $\theta_{0}$ or $\phi_{0}$ on the optimal coefficients that measure the reaction to changes in inflation or the output gap. Interestingly, the coefficient that gives the optimal reaction to inflation is quite robust to changes in either $\theta_{0}$ or $\phi_{0}$, because it always takes a rather low value ( $\mu_{6}=0.0016$ at the baseline calibration). The reaction to the output gap is stronger than the reaction to inflation (contradicting the original Taylor prescription), with a value $\mu_{8}=0.0064$ under the baseline calibration. ${ }^{16}$ The output gap

${ }^{16}$ Actually, it can be observed from (TR) that $\left(\mu_{6} / \mu_{8}\right)=\left(\phi_{1} / \gamma_{y}\right)$. The baseline calibration implies $\phi_{1}<\gamma_{y}$, which gives rise to an optimal coefficient is affected in a different way by changes in $\theta_{0}$ and $\phi_{0}$. If the output gap dynamics were more backward-looking (higher $\theta_{0}$ ), the optimal policy would react more strongly to the output gap (higher $\mu_{8}$ ). The reverse is observed (lower $\mu_{8}$ ) when inflation has a greater backward-looking component (higher $\phi_{0}$ ); the optimal policy will respond less aggressively to the output gap. Furthermore, the response coefficient to the lagged output gap $\left(\mu_{7}\right)$ will significantly decrease in absolute value.

Let us turn to discuss the implications of changes in the slope parameters, $\theta_{1}$ and $\phi_{1}$ (Figure 2). As implied by the definition of the $\mu$ 's in (TR), there is very little impact of either $\theta_{1}$ or $\phi_{1}$ on the structure of lags and leads. ${ }^{17}$ The only coefficient of this type that is affected by the slope coefficients is $\mu_{2}$, which is the one giving reactions to $R_{t-1}$. Nevertheless, the value of $\mu_{2}$ is rather insensitive to changes in the slope coefficients

policy with larger reactions to the output gap than to inflation. To reverse this result, either the slope of the Phillips curve should increase (higher $\phi_{1}$ ) or the central bank should have a weaker stabilizing preference for the output gap (lower $\gamma_{y}$ ).

17 The reaction to changes in $\phi_{1}$ is not visible in some of the cases plotted in Figure 2 because it overlaps the reaction to changes in $\theta_{1}$. In turn, both reactions are null (flat lines) and indistinguishable. 
Figure 2

\section{Coefficients of the Targeting Rule (TR) Depending on the Slope Parameters of the (AD) Equation, $\theta_{1}$, and the (AS) Equation, $\phi_{1}$}
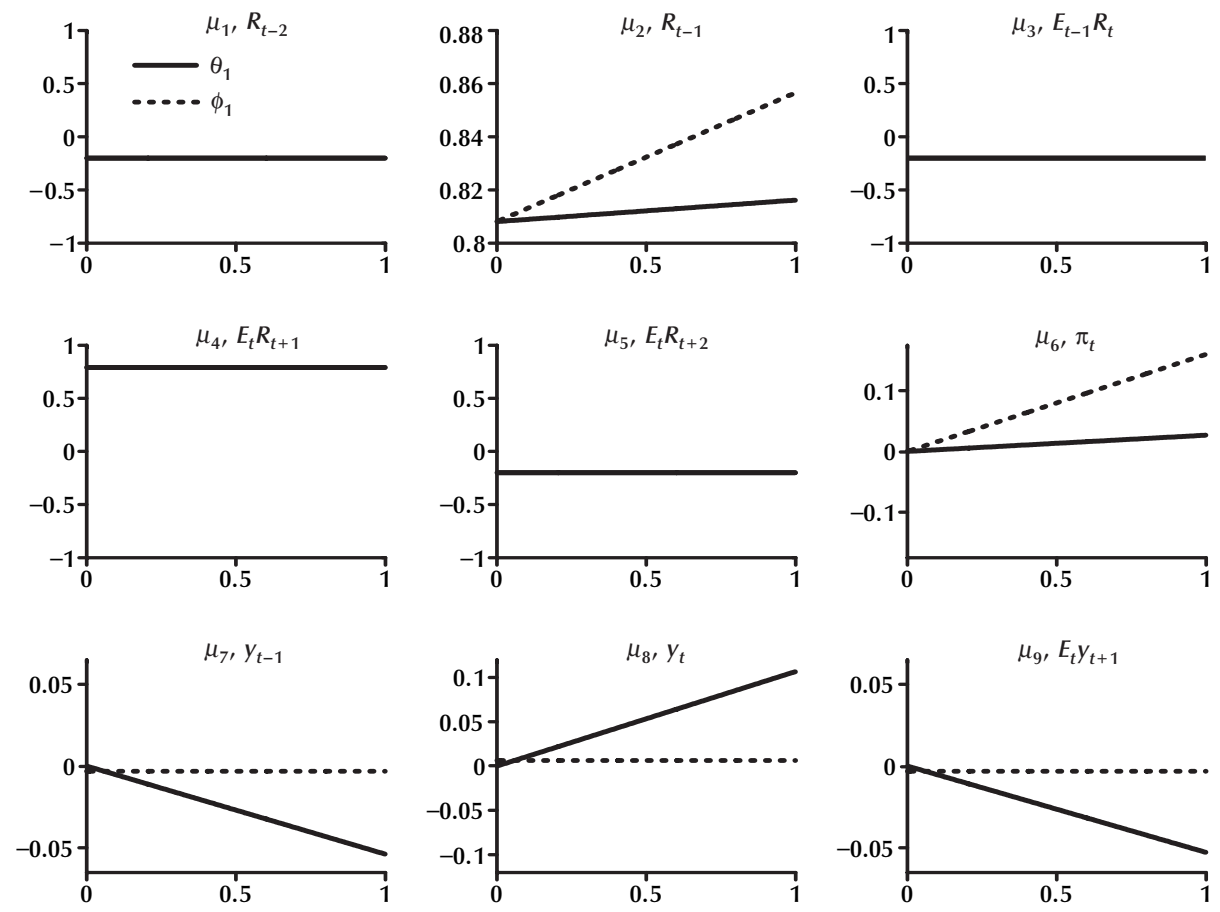

because it moves only within a very narrow range when altering $\phi_{1}$ from 0.0 to 1.0 (between 0.80 and 0.86 as shown in Figure 2). The impact of different settings for $\theta_{1}$ or $\phi_{1}$ on the other optimal coefficients of (TR) are also displayed in Figure 2. A higher $\mathrm{AD}$ curve slope $\left(\theta_{1}\right)$ entails higher responsiveness of the optimal policy to inflation deviations and the current output gap (higher $\mu_{6}$ and $\mu_{8}$ ). In addition, the reaction to both the past and expected future output gap would also be more significant (higher $\mu_{7}$ and $\mu_{9}$ in absolute value). Regarding the slope of the AS curve $\left(\phi_{1}\right)$, it determines only the coefficients on inflation and the lagged nominal interest rate (see Figure 2). Both coefficients $\left(\mu_{6}\right.$ and $\left.\mu_{2}\right)$ are positively affected by a higher $\phi_{1}$.

Finally, it can be observed in (TR) that the parameters that provide the central-bank stabilizing preference, $\gamma_{y}$ and $\gamma_{R}$, also play some role in the design of the optimal coefficients. In particular, their values have influence on the way the optimal policy should respond to inflation $\left(\mu_{6}\right)$ and the output gap terms $\left(\mu_{7}, \mu_{8}\right.$, and $\left.\mu_{9}\right)$ because the coefficients on the internal dynamics of the nominal interest rate (from $\mu_{1}$ to $\mu_{5}$ ) do not depend on either $\gamma_{y}$ or $\gamma_{R}$. Figure 3 shows the reaction of the $\mu$ 's coefficients (if any). ${ }^{18}$ When the preference for stabilizing the output gap rises (higher $\gamma_{y}$ ), the reactions of the nominal interest rate involving output gap terms become more significant as implied by a higher (absolute) value of the coefficients $\mu_{7}, \mu_{8}$, and $\mu_{9}$. The inflation coefficient $\mu_{6}$ is not affected by a change in $\gamma_{y}$. In the case of a central bank more oriented to stabilizing the nominal interest rate (higher $\gamma_{R}$ ), the inflation and output gap coefficients lose ground rapidly. As shown in Figure 3, they approach zero as $\gamma_{R}$ increases.

\footnotetext{
${ }^{18}$ Note that the reactions overlap in many cases displayed in Figure 3
} because there is no influence from either $\gamma_{y}$ or $\gamma_{R}$. 
Figure 3

\section{Coefficients of the Targeting Rule (TR) Depending on the Central-Bank Stabilizing Preference Parameters, $\gamma_{y}$ and $\gamma_{R}$}
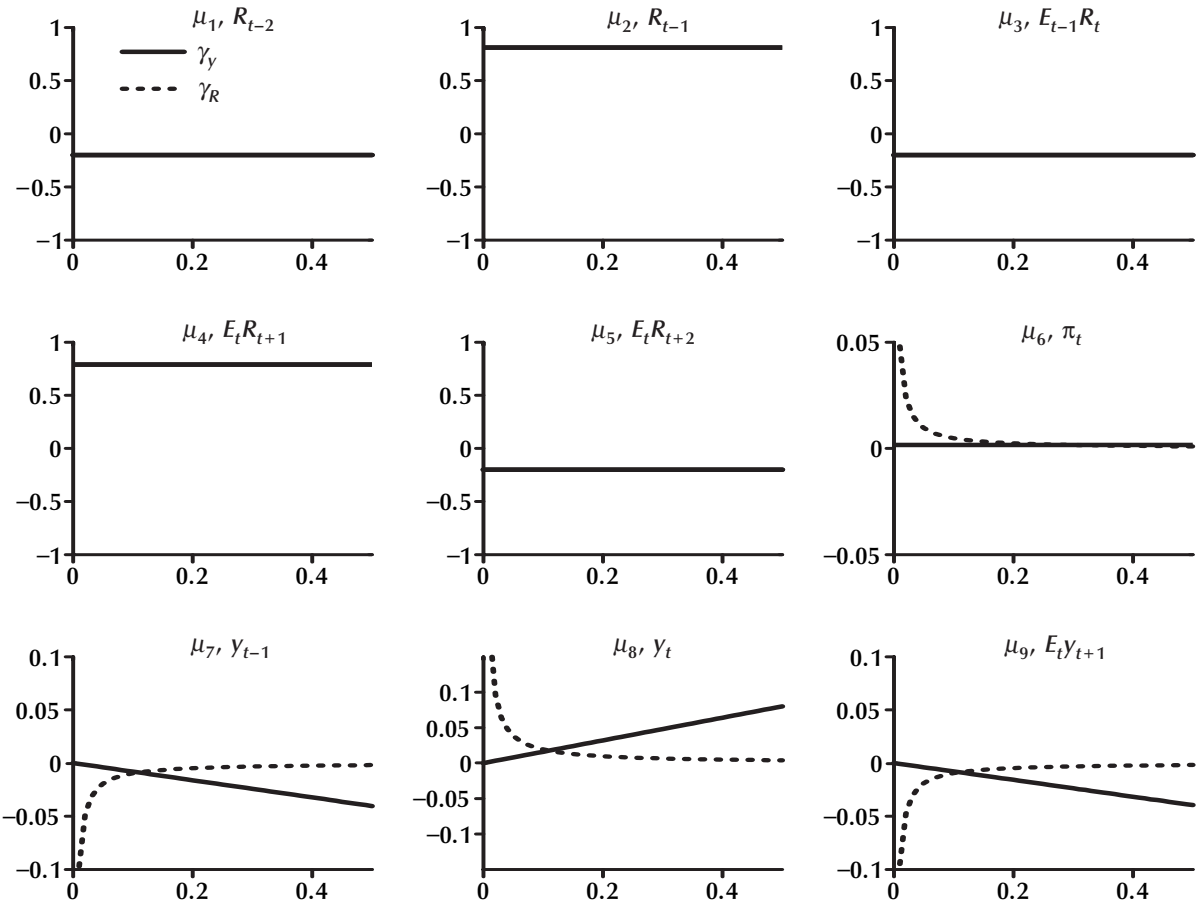

Summarizing, the backward-looking coefficients of the (AD)-(AS) structure are of great importance for the computation of the optimal interest-rate reaction function. A counterbalance assignment for optimal policy was issued: More backward-lookingness in the economy would lead to more forward-lookingness in monetary policy actions and vice versa. The slope coefficients matter only for the size of the responses to changes in the output gap or inflation. Thus, the slope of the (AD) curve has a positive impact on the reactions to inflation and the output gap while the slope of the (AS) curve exerts a positive impact only on the first of the two. The central-bank stabilizing preference, expressed by the weights of its target variables in (L), also plays a role in the determination of the optimal reaction to inflation and the output gap.

\section{...AND IN A MIS-SPECIFIED MODEL}

The analysis of the previous section was done assuming that the central bank was able to correctly identify the parameters of the (AD)-(AS) relationships. However, this is something that should not be taken for granted, because the central bank may make a mistake when estimating the true values of the parameters. Here, we will assume that the central bank feels confident about the canonical (AD)-(AS) model as a good representation of the economy but some identification error may arise when estimating $\theta_{0}, \theta_{1}, \phi_{0}$, or $\phi_{1}$. Perhaps the central bank should no longer apply (TR) because its optimality vanishes if the model parameters are wrongly identified. In other words, the possibility of generating macroeconomic instability may discourage the central bank from using the model-dependent (TR). Alternatively, 


\section{Table 4}

Stabilizing Performance of (TR) with One Mistake on Parameter Identification Relative to Either Optimal Policy (denoted by superscript *) or Taylor Rule (denoted by superscript TayR)

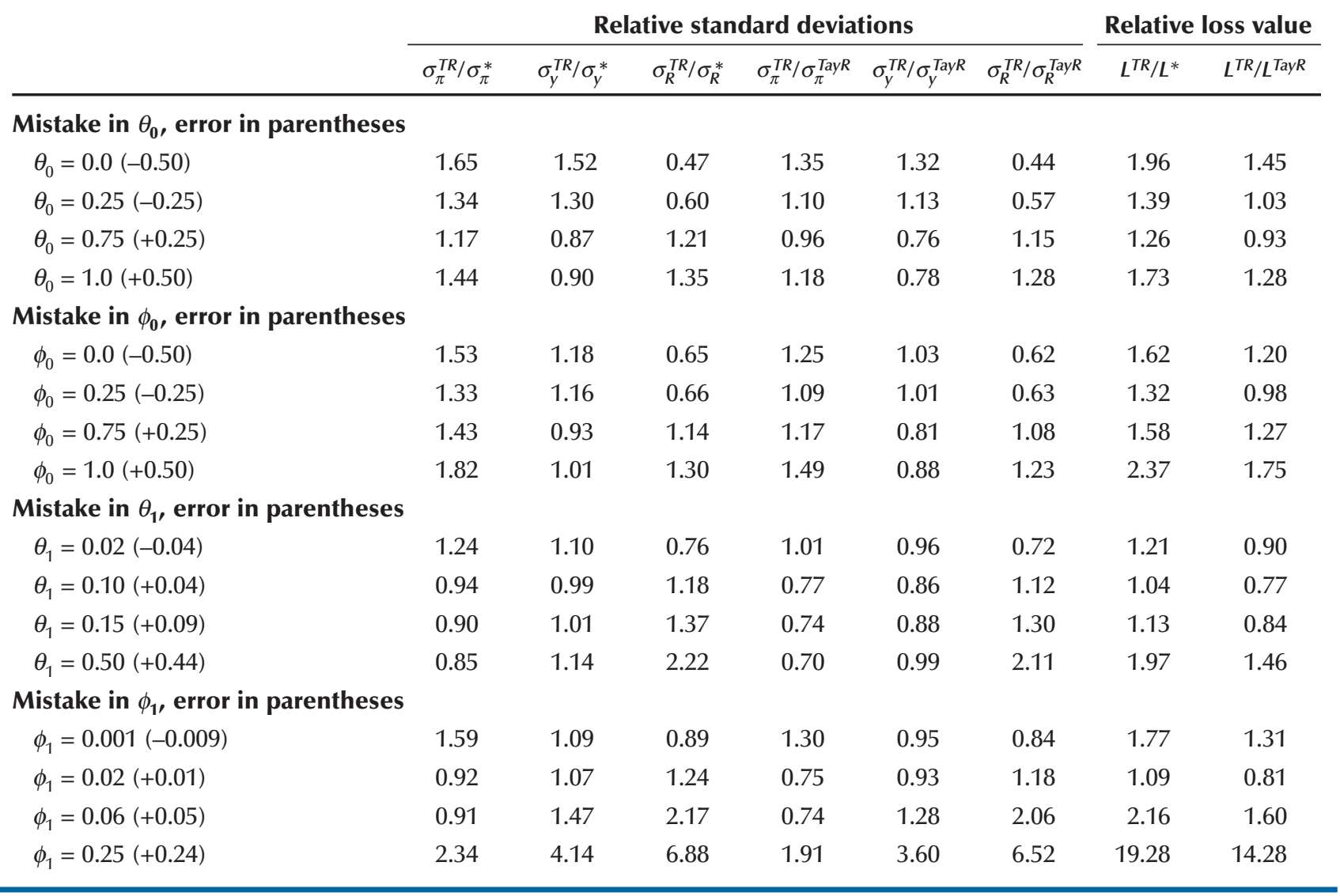

the central bank could rely on a model-invariant policy rule, such as the Taylor-type rule (TayR), for example. This issue is going to be examined in exercises of policy simulation assuming either one or two mistakes in the identification of the (AD)-(AS) model parameters.

Our first simulation exercise consists of evaluating the performance of the (TR) when the central bank makes only one mistake in the identification of the model parameters. More concretely, it is supposed that the true parameters are those of the baseline calibration (Table 1) and the central bank is capable of correctly identifying all of them except one. To measure the stabilizing performance, we compute the standard deviations of the target variables and compare them with those obtained if the model parameters had been suc- cessfully identified. In addition, the unconditional expectation of the central-bank loss function $(L)$ will also be computed to provide an overall performance mark. This (long-run) loss value has been used to rank alternative monetary policy rules in recent work such as Levin and Williams (2003), Adalid et al. (2005), Smets (2003), Walsh (2005), Casares (2006), and Coenen (2006).

Table 4 reports several cases of the performance of (TR) with one identification mistake. The results are expressed in relative terms with respect to both the well-identified (optimal) targeting rule and the calibrated Taylor-type rule (TayR). ${ }^{19}$ The former will tell us the deviation from optimal-

\footnotetext{
19 The numerical values of the annualized percent standard deviations with the well-identified (TR) and (TayR) were reported in Table 2.
} 


\section{Figure 4}

\section{Performance of Targeting Rules When One Parameter Is Mistakenly Identified}
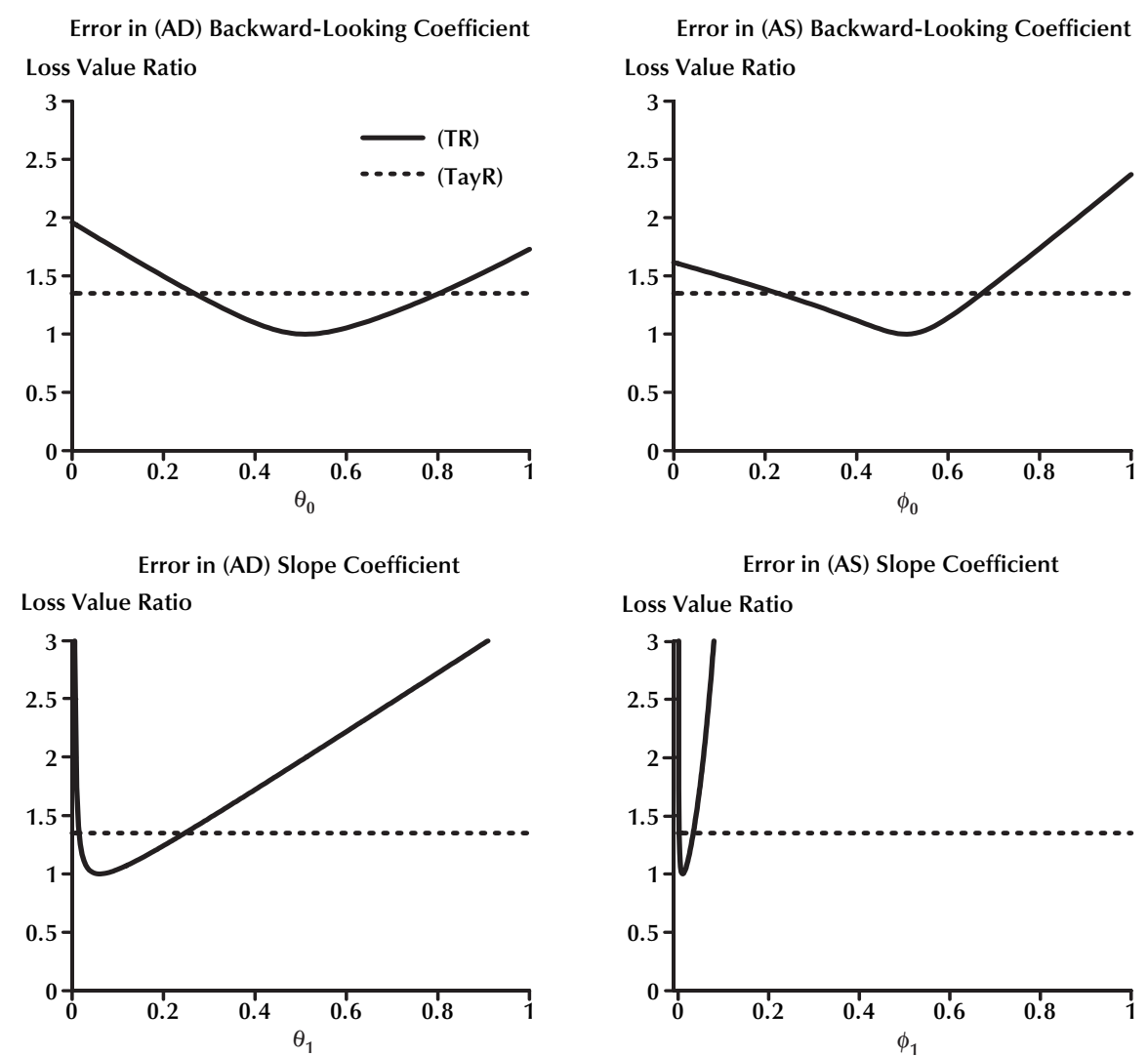

ity, and the latter will tell us the deviation from applying a model-independent simple rule such as (TayR). The first line of Table 4 shows what happens when the central bank mistakenly believes that the output gap is purely forwardlooking and sets $\theta_{0}=0.0$ instead of its true value, $\theta_{0}=0.5$. This mistake will make the policy rule much more backward-looking as the lagged coefficients, $\mu_{1}$ and $\mu_{2}$, gain significance; whereas, the lead coefficients, $\mu_{4}$ and $\mu_{5}$, lose significance. As a consequence, the inflation standard deviation will be 65 percent higher than that obtained with the optimal policy $\left(\sigma_{\pi}^{T R} / \sigma_{\pi}^{*}=1.65\right)$, the output gap standard deviation will be 52 percent higher $\left(\sigma_{y}^{T R} / \sigma_{y}^{*}=1.52\right)$, and the interest-rate volatility will drop by more than one-half $\left(\sigma_{R}^{T R} / \sigma_{R}^{*}=0.47\right)$. Moreover, the calibrated (TayR) outperforms the
(TR) with that mistake because the variabilities of inflation and the output gap are significantly higher with the latter $\left(\sigma_{\pi}^{T R} / \sigma_{\pi}^{\text {TayR }}=1.35\right.$ and $\left.\sigma_{y}^{T R} / \sigma_{y}^{\text {TayR }}=1.32\right)$. In loss-value terms, it is reported $L^{T R} / L^{*}=1.96$ and $L^{T R} / L^{T a y R}=1.45$, which means that the incorrect identification of $\theta_{0}$ gives rise to a 96 percent higher loss value compared with the optimal (TR) and still a higher 45 percent loss value in comparison with (TayR). In this particular example the identification mistake gives rise to a substantial worsening of monetary policy performance with (TR), which leads us to recommend its replacement by the model-independent (TayR). With smaller deviations of the specified $\theta_{0}$ from the true parameter such as $\theta_{0}=0.25$ or $\theta_{0}$ $=0.75$, the misspecified targeting rule provides a stabilizing performance closer to the well-specified 


\section{Table 5}

\section{Allowance Intervals for a Mistakenly Identified (TR) Over the Calibrated (TayR), $\left(L^{T R} / L^{*}\right)<\left(L^{\text {TayR }} / L^{*}\right)=1.35$}

Allowance interval

\begin{tabular}{lcc} 
& Allowance interval & True value \\
\hline One mistake & & $\theta_{0}=0.5$ \\
$\theta_{0}$ & $\theta_{0} \in[0.28,0.80]$ & $\phi_{0}=0.5$ \\
$\phi_{0}$ & $\phi_{0} \in[0.24,0.67]$ & $\theta_{1}=0.06$ \\
$\theta_{1}$ & $\theta_{1} \in[0.016,0.245]$ & $\phi_{1}=0.01$ \\
$\phi_{1}$ & $\phi_{1} \in[0.002,0.033]$ & $\theta_{0}=\phi_{0}=0.5$ \\
Two mistakes & & $\theta_{0}=\phi_{0}=0.5$ \\
$\theta_{0}$ with $\phi_{0}=0.40$ & $\theta_{0} \in[0.42,0.64]$ & $\theta_{0}=\phi_{0}=0.5$ \\
$\theta_{0}$ with $\phi_{0}=0.25$ & $\theta_{0} \in[0.48,0.52]$ & $\theta_{0}=\phi_{0}=0.5$ \\
$\phi_{0}$ with $\theta_{0}=0.40$ & $\phi_{0} \in[0.42,0.61]$ & $\varnothing$
\end{tabular}

targeting rule, although it still provides significant differences in the standard deviations of the target variables and the loss function (see Table 4).

Figure 4 contains graphs of the loss value ratio $L^{T R} / L^{*}$ for different model misidentifications. The upper-left graph represents the case of an identification mistake on the output gap backwardlooking coefficient $\theta_{0}$. The value of $L^{T R} / L^{*}$ has a minimal value of 1 when there is no identification mistake $\left(\theta_{0}=0.5\right)$ and starts rising when the value of $\theta_{0}$ deviates to the right or the left. There is a horizontal dotted line that marks the ratio obtained with the implementation of the model-invariant (TayR). The overall performance of (TayR) is better than the mistakenly identified (TR) when the solid line is above the dotted line. For a mistake in $\theta_{0}$, (TayR) happens to be preferred when $\theta_{0}$ takes a value either lower than 0.28 or higher than 0.80 . Let us define that interval as the "allowance interval” to keep the wrongly identified (TR) over the calibrated (TayR). ${ }^{20}$ As shown in Table 5, the central bank can make an identifying mistake in the range $\theta_{0} \in[0.28,0.80]$ and still carry out a monetary policy with stabilizing performance superior to that of the calibrated (TayR).

\footnotetext{
${ }^{20}$ The loss value obtained with the calibrated (TayR) is 35 percent higher than the one obtained with the well-designed (TR). Therefore, the "allowance interval" can also be understood as the parameter set that results in a loss value that never exceeds the minimum by more than 35 percent.
}

Results are alike if the backward-looking coefficient of inflation, $\phi_{0}$, is incorrectly identified. The stabilizing capacity of the mistakenly identified (TR) is poor when the identification error is of large magnitude (see lines with $\phi_{0}=0.0$ or $\phi_{0}=1.0$ in Table 4). The upper-right graph of Figure 4 shows that the wrong $\phi_{0}$ must lie inside the range $\phi_{0} \in[0.24,0.67]$ to yield a loss value lower than the one produced by applying the calibrated (TayR). Precisely, this is the allowance interval for a mistake in $\phi_{0}$ reported in Table 5.

Table 4 and Figure 4 also show the performance of (TR) if the identification mistake is made in one of the slope coefficients, $\theta_{1}$ or $\phi_{1}$. When looking at the bottom panels of Figure 4, one can clearly observe that a good identification for the slope coefficient of the (AS) equation $\phi_{1}$ is required to avoid bad policies, whereas the (AD) slope coefficient $\theta_{1}$ seems to be less important. (Note how quickly the loss value ratio rises when $\phi_{1}$ deviates from its true value of 0.01.) A slight mistake such as setting $\phi_{1}=0.02$ instead of $\phi_{1}=$ 0.01 would result in nearly a 10 percent higher loss value (see Table 4). With a higher mistake $\left(\phi_{1}=0.06\right)$, the standard deviations and the loss value change substantially, relative to the optimal policy. Moreover, the loss value ratio relative to (TayR) is 1.60, which means that (TayR) would clearly outperform a (TR) holding this identification error. By contrast, the (AD) slope, $\theta_{1}$, allows 


\section{Table 6}

Stabilizing Performance of (TR) with Two Mistakes on Parameter Identification Relative to Either Optimal Policy (denoted by superscript *) or Taylor Rule (denoted by superscript TayR)

\begin{tabular}{|c|c|c|c|c|c|c|c|c|}
\hline \multirow{2}{*}{$\begin{array}{l}\text { Mistakes in } \theta_{0} \text { and } \phi_{0}, \\
\text { error in parentheses }\end{array}$} & \multicolumn{6}{|c|}{ Relative standard deviations } & \multicolumn{2}{|c|}{ Relative loss value } \\
\hline & $\sigma_{\pi}^{T R} / \sigma_{\pi}^{*}$ & $\sigma_{y}^{T R} / \sigma_{y}^{*}$ & $\sigma_{R}^{T R} / \sigma_{R}^{*}$ & $\sigma_{\pi}^{T R} / \sigma_{\pi}^{T a y R}$ & $\sigma_{y}^{T R} / \sigma_{y}^{T a y R}$ & $\sigma_{R}^{T R} / \sigma_{R}^{\text {Tay } R}$ & $L^{T R} / L^{*}$ & $L^{T R} / L^{\operatorname{Tay} R}$ \\
\hline$\theta_{0}=0.40(-0.10), \quad \phi_{0}=0.0(-0.50)$ & 1.89 & 1.72 & 0.34 & 1.55 & 1.49 & 0.32 & 2.50 & 1.85 \\
\hline$\theta_{0}=0.40(-0.10), \quad \phi_{0}=0.25(-0.25)$ & 1.60 & 1.52 & 0.47 & 1.31 & 1.32 & 0.45 & 1.88 & 1.39 \\
\hline$\theta_{0}=0.40(-0.10), \quad \phi_{0}=0.75(+0.25)$ & 1.96 & 1.23 & 1.11 & 1.61 & 1.07 & 1.05 & 2.63 & 1.95 \\
\hline$\theta_{0}=0.40(-0.10), \quad \phi_{0}=1.0(+0.50)$ & 5.25 & 3.61 & 1.07 & 4.30 & 3.14 & 1.01 & 17.3 & 12.8 \\
\hline$\theta_{0}=0.25(-0.25), \quad \phi_{0}=0.0(-0.50)$ & 2.06 & 1.80 & 0.25 & 1.69 & 1.56 & 0.24 & 2.91 & 2.15 \\
\hline$\theta_{0}=0.25(-0.25), \quad \phi_{0}=0.25(-0.25)$ & 1.79 & 1.60 & 0.36 & 1.47 & 1.39 & 0.34 & 2.24 & 1.66 \\
\hline$\theta_{0}=0.25(-0.25), \quad \phi_{0}=0.75(+0.25)$ & 4.83 & 3.31 & 1.02 & 3.96 & 2.87 & 0.97 & 14.6 & 10.8 \\
\hline$\theta_{0}=0.25(-0.25), \quad \phi_{0}=1.0(+0.50)$ & 3.77 & 2.89 & 0.39 & 3.09 & 2.51 & 0.37 & 9.16 & 6.78 \\
\hline$\phi_{0}=0.40(-0.10), \quad \theta_{0}=0.0(-0.50)$ & 1.58 & 1.35 & 0.47 & 1.30 & 1.17 & 0.45 & 1.74 & 1.29 \\
\hline$\phi_{0}=0.40(-0.10), \quad \theta_{0}=0.25(-0.25)$ & 1.50 & 1.36 & 0.51 & 1.23 & 1.18 & 0.48 & 1.62 & 1.20 \\
\hline$\phi_{0}=0.40(-0.10), \quad \theta_{0}=0.75(+0.25)$ & 1.76 & 1.25 & 0.83 & 1.44 & 1.08 & 0.79 & 2.12 & 1.57 \\
\hline$\phi_{0}=0.40(-0.10), \quad \theta_{0}=1.0(+0.50)$ & 2.13 & 1.43 & 0.71 & 1.75 & 1.24 & 0.67 & 2.91 & 2.15 \\
\hline$\phi_{0}=0.25(-0.25), \quad \theta_{0}=0.0(-0.50)$ & 1.85 & 1.58 & 0.33 & 1.52 & 1.37 & 0.31 & 2.34 & 1.73 \\
\hline$\phi_{0}=0.25(-0.25), \quad \theta_{0}=0.25(-0.25)$ & 1.79 & 1.60 & 0.36 & 1.47 & 1.39 & 0.34 & 2.24 & 1.66 \\
\hline$\phi_{0}=0.25(-0.25), \quad \theta_{0}=0.75(+0.25)$ & 2.25 & 1.69 & 0.49 & 1.85 & 1.47 & 0.46 & 3.28 & 2.43 \\
\hline$\phi_{0}=0.25(-0.25), \quad \theta_{0}=1.0(+0.50)$ & 2.25 & 1.61 & 0.34 & 1.85 & 1.40 & 0.32 & 3.20 & 2.37 \\
\hline
\end{tabular}

a greater margin for an identification error without causing severe damage to the stabilizing performance. Medium-size mistakes $\left(\theta_{1}=0.02\right.$ or $\left.\theta_{1}=0.10\right)$ result in moderate increases of the loss value, which remains lower than the value obtained with (TayR). The consequences of making one identification mistake on $\theta_{1}$ are only grave when the parameter is assumed to be much lower than its real value (see $\theta_{1}$ approaching zero in the bottom left panel of Figure 4). Summarizing, the allowance ranges for making mistakes in specifying $\theta_{1}$ or $\phi_{1}$ while still preferring (TR) to the calibrated (TayR) are, respectively, $\theta_{1} \in[0.016,0.245]$ and $\phi_{1} \in$ $[0.002,0.033]$. Therefore, the allowance interval is substantially narrower for the (AS) slope coefficient $\phi_{1}$.

Our second policy exercise consists of assuming that the central bank makes mistakes in identifying both backward-looking parameters, $\theta_{0}$ and $\phi_{0}$, while the slope coefficients, $\theta_{1}$ and $\phi_{1}$, are correctly estimated (see Table 6 and Figure 5). Actually, one of the misidentifications is set to be rather small by setting the parameter at either 0.40 or 0.25 instead of its true value, 0.50 . The other wrong parameter takes a value within the set $[0.0,0.25,0.75,1.0]$ in Table 6 and the full range of possible values in Figure 5. The overall impression perceived in Table 6 is that the implementation of a (TR) with two identification mistakes always leads to significant increases in the variability of inflation and the output gap relative to optimal policy while the interest-rate variability decreases. The deviations are quantitatively large in all the cases, even in those with smaller identification mistakes. For example, when $\theta_{0}=0.40$ and $\phi_{0}=0.25$ instead of their true values at 0.50 , the inflation and output gap standard deviations are, respectively, 60 percent and 52 percent higher than the ones obtained with the optimal (wellidentified) policy. By jointly looking at Table 4 


\section{Figure 5}

\section{Performance of Targeting Rules When Either One Parameter (solid lines) or Two Parameters (dashed and dash-dotted lines) Are Mistakenly Identified}

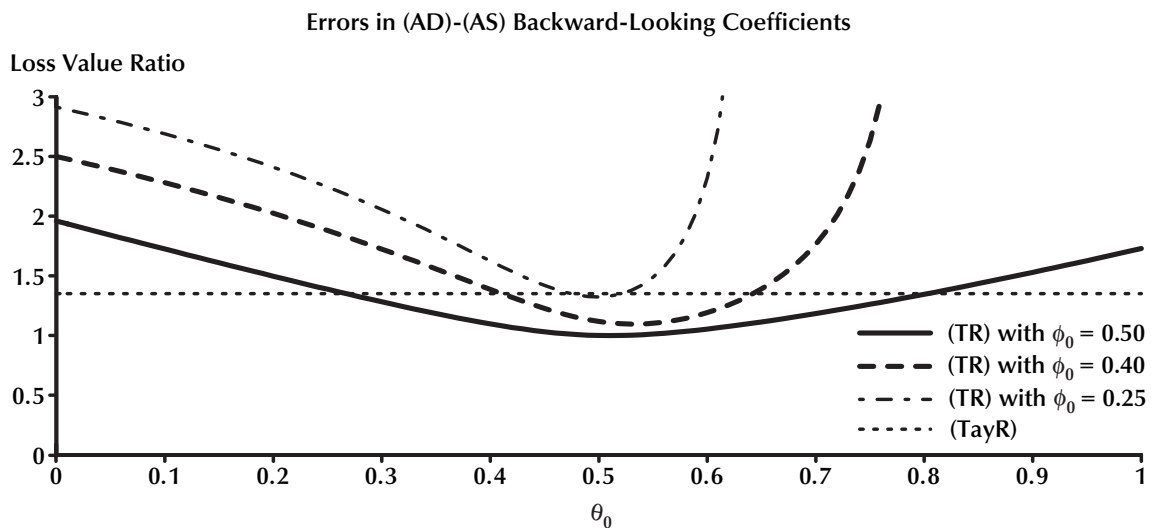

Errors in (AD)-(AS) Backward-Looking Coefficients

Loss Value Ratio

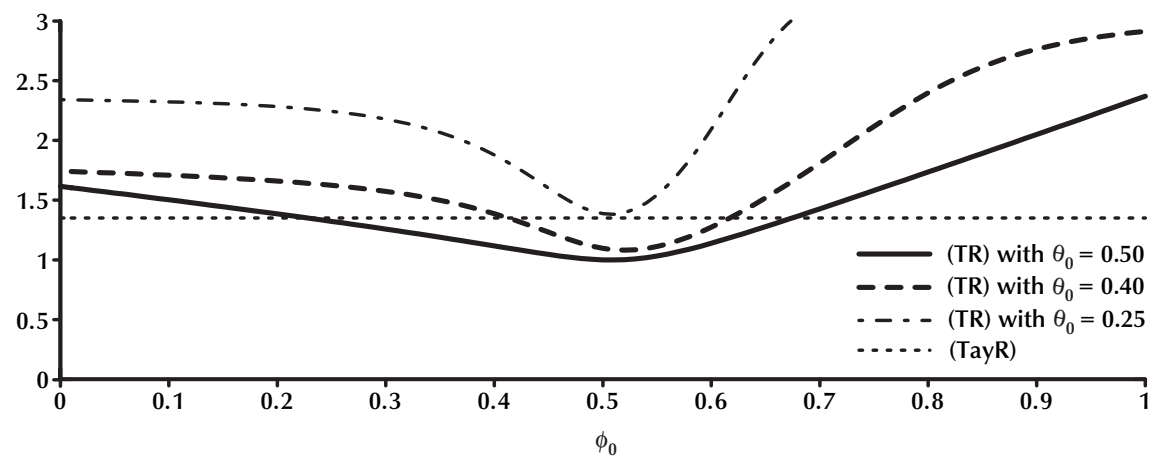

and Table 6, one can realize that making a single "large" mistake such as $\theta_{0}=0.0$ in Table 4 is roughly equivalent to making two "small" mistakes such as $\theta_{0}=0.40$ and $\phi_{0}=0.25$ in Table 6 . The standard deviations and loss function ratios are similar in both cases. Thus, allowing the central bank to make two identification mistakes implies that the stabilizing performance of the wrong (TR) is substantially poorer than the one with a single mistake. If we compare its performance with that of the model-invariant (TayR), we come to the conclusion of recommending the implementation of (TayR) when there is moderate uncertainty on both $\theta_{0}$ and $\phi_{0}$. In the last column of Table 6 the ratio $L^{T R} / L^{T a y R}$ is always clearly greater than 1 , which means that the loss value when applying (TayR) is significantly lower than the loss value obtained by applying the mistakenly identified (TR). With one mistake (see Table 4 ), $L^{T R} / L^{\text {TayR }}$ was greater than 1 in 10 of 16 total cases.

The same conclusion is reached by looking at the graphical display of Figure 5. The plots show that the deviation from optimal policy (measured by the loss value ratio defined above) rapidly rises as the parameters deviate from their true value $(0.5) .^{21}$ The ratios are higher as the model param-

${ }^{21}$ The solid lines of Figure 5 represent cases with only one identification mistake. Accordingly, the solid line in the upper panel of Figure 5 is also shown in the upper-left panel of Figure 4. Likewise, the solid line in the lower panel of Figure 5 is also displayed as the upper-right panel of Figure 4. 
eters deviate more from their true value (compare dashed and dash-dotted lines in the two panels of Figure 5). Meanwhile, the loss value ratio relative to optimal policy when implementing (TayR) is represented by a flat (dotted) line in Figure 5 because its design is independent of the model parameters. With two identification mistakes, (TR) performs better than the model-independent (TayR) only if the mistakes are very small. The allowance intervals can be seen from Figure 5 as the parameter interval in which the loss value ratio with (TR) is below the dotted horizontal line. As Table 5 informs, these allowance intervals are clearly narrower than the ones found under a single identification error.

In review, our simulation results give support to the use of a model-dependent targeting rule for monetary policy design only if the central bank has little uncertainty on the identification of the true parameters of the (AD)-(AS) model. By contrast, a moderate uncertainty on model parameters (e.g., significant errors in the two backward-looking coefficients) can result in a substantial increase of macroeconomic instability. In such situations, a model-independent rule such as (TayR) is more appropriate for monetary policy conduct because of its better stabilizing performance.

\section{CONCLUSIONS}

This article has examined the influence of model parameters on monetary policy design under targeting rules. The reference model consists of one pair of (AD)-(AS) equations that allow for both backward-looking and forward-looking dynamics on both inflation and the output gap. Using Woodford's timeless perspective approach, we derived the targeting rule for the hybrid (AD)-(AS) model as a nine-term reaction function of the nominal interest rate. Coincidently, the targeting rule resembles Taylor's (1993) famous policy prescription: The nominal interest rate must positively respond to current fluctuations of inflation and the output gap. Also, the reaction function for the nominal interest rate includes rich internal dynamics (with coefficients on two lags, two leads, and its expected value computed one period ago) and a reaction to one lag and one lead of the output gap.

The analysis of the influence of the model parameters on the monetary policy design was implemented in two different scenarios. First, it was assumed that the central bank can exactly identify the true values of the model parameters (in the section on sensitivity analysis in a wellspecified model). In this case, the degree of backward-lookingness of either inflation or the output gap is key for the optimal design of monetary policy. Thus, a "counterbalance assignment" was set: Monetary policy should be more backward-looking when either inflation or the output gap are more forward-looking, and monetary policy should turn more forward-looking when either one happens to be more backward-looking. This result is an extension of similar policy recommendations from Giannoni and Woodford (2003), Smets (2003), and Leitemo (2006). The role of other model parameters (slope coefficients in (AD)-(AS) and central-bank policy parameters) is limited in determining the response coefficients involving inflation or the output gap because these parameters have no practical influence on the internal interest-rate dynamics.

The second policy scenario incorporates the possibility that the central bank makes mistakes when identifying the parameters of the (AD)-(AS) equations (see the previous section). With such uncertainty, the model-dependent targeting rule is no longer optimal because it contains the identification error. As a result, the stabilizing performance of the targeting rule may worsen in a significant way. As expected, the stabilizing capacity of the targeting rule is poorer with larger identification mistakes. This scenario may lead the central bank to conduct monetary policy with a model-independent rule. Concretely, some simulation exercises show that a calibrated Taylortype rule performs better than the targeting rule in cases of moderate or severe uncertainty on the coefficients of the (AD)-(AS) equations. This finding can be understood as a call for a more cautious monetary policy design when there is model uncertainty. It brings back the old prescription from Brainard (1967), contradicting the opposite recommendation recently found in the literature 
(Onatski and Stock, 2002; Söderström, 2002; Leitemo and Söderström, 2004; and Giannoni, 2006).

\section{REFERENCES}

Adalid, Ramón; Coenen, Günter; McAdam, Peter and Siviero, Stefano. "The Performance and Robustness of Interest-Rate Rules in Models of the Euro Area." International Journal of Central Banking, May 2005, 1(1), pp. 95-132.

Amato, Jeffery D. and Laubach, Thomas. "Estimation and Control of an Optimization-Based Model with Sticky Prices and Wages." Journal of Economic Dynamics and Control, May 2003, 27(7), pp. 1181215.

Brainard, William C. "Uncertainty and the Effectiveness of Policy." American Economic Review, May 1967, 57(2), pp. 411-25.

Calvo, Guillermo A. "Staggered Pricing in a UtilityMaximizing Framework." Journal of Monetary Economics, September 1983, 12(3), pp. 383-98.

Casares, Miguel. "Monetary Policy Rules in a New Keynesian Euro Area Model.” Journal of Money, Credit, and Banking, 2006 (forthcoming).

Christiano, Lawrence J.; Eichenbaum, Martin and Evans, Charles L. "Nominal Rigidities and the Dynamic Effects of a Shock to Monetary Policy." Journal of Political Economy, February 2005, 113(1), pp. 1-45.

Clarida, Richard; Galí, Jordi and Gertler, Mark. "The Science of Monetary Policy: A New Keynesian Perspective." Journal of Economic Literature, December 1999, 37(4), pp. 1661-707.

Coenen, Günter. "Inflation Persistence and Robust Monetary Policy Design.” Journal of Economic Dynamics and Control, 2006 (forthcoming).

Fuhrer, Jeffrey C. "Habit Formation in Consumption and Its Implications for Monetary-Policy Models." American Economic Review, June 2000, 90(3), pp. 367-90.
Fuhrer, Jeffrey C. and Moore, George. "Inflation Persistence.” Quarterly Journal of Economics, February 1995, 110(1), pp. 127-59.

Galí, Jordi. "How Well Does the IS-LM Model Fit Postwar U.S. Data?" Quarterly Journal of Economics, May 1992, 107(2), pp. 709-38.

Galí, Jordi and Gertler, Mark. "Inflation Dynamics: A Structural Econometric Analysis." Journal of Monetary Economics, October 1999, 44(2), pp. 195222.

Giannoni, Marc P. "Robust Optimal Monetary Policy in a Forward-Looking Model with Parameter and Shock Uncertainty." Journal of Applied Econometrics, 2006 (forthcoming).

Giannoni, Marc. P. and Woodford, Michael. "Optimal Interest-Rate Rules: I. General Theory.” NBER Working Paper 9419, National Bureau of Economic Research, 2002.

Giannoni, Marc P. and Woodford, Michael. "How Forward-Looking Is Optimal Monetary Policy?" Journal of Money, Credit, and Banking, December 2003, 35(6, Part 2), pp. 1425-69.

Jensen, Christian, and McCallum, Bennett T. "The Non-Optimality of Proposed Monetary Policy Rules Under Timeless Perspective Commitment." Economics Letters, October 2002, 77(2), pp. 163-8.

Leitemo, Kai. "Inflation Targeting Rules: HistoryDependent or Forward-Looking?” Working paper, February 2006.

Leitemo, Kai and Söderström, Ulf. "Robust Monetary Policy in the New-Keynesian Framework.” CEPR Working Paper No. 4805, Centre for Economic Policy Research, 2004.

Levin, Andrew T.; Onatski, Alexei; Williams, John C. and Williams, Noah. "Monetary Policy Under Uncertainty in Micro-Founded Macroeconometric Models," in Mark Gertler and Kenneth Rogoff, eds., NBER Macroeconomics Annual 2005, MIT Press 2006 (forthcoming). 
Levin, Andrew T. and Williams, John C. "Robust Monetary Policy with Competing Reference Models." Journal of Monetary Economics, July 2003, 50(5), pp. 945-75.

Lindé, Jesper. "Estimating New-Keynesian Phillips Curves: A Full Information Maximum Likelihood Approach.” Journal of Monetary Economics, September 2005, 52(6), pp. 1135-49.

McCallum, Bennett T. "Issues in the Design of Monetary Policy Rules,” in John B. Taylor and Michael Woodford, eds., Handbook of Macroeconomics. Volume 1, Part 3, Chap. 23. Amsterdam: North-Holland, 1999, pp. 1483-530.

McCallum, Bennett T. "Multiple-Solution Indeterminacies in Monetary Policy Analysis.' Journal of Monetary Economics, July 2003, 50(5), pp. 1153-75.

McCallum, Bennett T. "What Is the Proper Perspective for Monetary Policy Optimality?” Bank of Japan, Monetary and Economic Studies, October 2005.

McCallum, Bennett T. and Nelson, Edward. "Targeting Versus Instrument Rules for Monetary Policy." Federal Reserve Bank of St. Louis Review, September/October 2005, 87(5), pp. 597-611.

Moessner, Richhild. “Optimal Discretionary Policy and Uncertainty about Inflation Persistence.” Working Paper No. 540, European Central Bank, 2005.

Moreno, Antonio. "Reaching Inflation Stability." Journal of Money, Credit, and Banking, August 2004, 36(4), pp. 801-25.

Onatski, Alexei and Stock, James H. "Robust Monetary Policy Under Model Uncertainty in a Small Model of the U.S. Economy." Macroeconomic Dynamics, February 2002, 6(1), pp. 85-110.

Preston, Bruce. “Adaptive Learning, Forecast-Based Instrument Rules and Monetary Policy." Journal of Monetary Economics, 2006 (forthcoming).

Smets, Frank. "Maintaining Price Stability: How Long Is the Medium Term?" Journal of Monetary Economics, September 2003, 50(6), pp. 1293-309.
Söderström, Ulf. "Monetary Policy with Uncertain Parameters.” Scandinavian Journal of Economics, 2002, 104(1), pp. 125-45.

Svensson, Lars E.O. "Inflation Targeting as a Monetary Policy Rule.” Journal of Monetary Economics, June 1999, 43(3), pp. 607-54.

Svensson, Lars E.O. "Inflation Targeting: Should It Be Modeled as an Instrument Rule or a Targeting Rule?” European Economic Review, April 2002, 46(4-5), pp. 771-80.

Svensson, Lars E.O. "What Is Wrong with Taylor Rules? Using Judgment in Monetary Policy Through Targeting Rules." Journal of Economic Literature, June 2003, 41(2), pp. 426-77.

Svensson, Lars E.O. “Targeting Versus Instrument Rules for Monetary Policy: What Is Wrong with McCallum and Nelson?" Federal Reserve Bank of St. Louis Review, September/October 2005, 87(5), pp. 613-25.

Taylor, John B. "Discretion Versus Policy Rules in Practice.” Carnegie-Rochester Conference Series on Public Policy, December 1993, 39(0), pp. 195-214.

Walsh, Carl E. "Endogenous Objectives and the Evaluation of Targeting Rules for Monetary Policy." Journal of Monetary Economics, July 2005, 52(5), pp. 889-911.

Woodford, Michael. "How Should Monetary Policy Be Conducted in an Era of Price Stability? Commentary." New Challenges for Monetary Policy, symposium sponsored by the Federal Reserve Bank of Kansas City, Jackson Hole, WY, August 26-28, 1999, pp. 277-316.

Woodford, Michael. Interest and Prices: Foundations of a Theory of Monetary Policy. Princeton, NJ: Princeton University Press, 2003a.

Woodford, Michael. "Optimal Interest-Rate Smoothing," Review of Economic Studies, October 2003b, 70(4), pp. 861-86. 


\section{APPENDIX}

\section{Optimality Discussion}

As argued by Jensen and McCallum (2002), Woodford's "timeless perspective” targeting rule (TR) is suboptimal if the optimality criterion is to minimize the unconditional expectation of the loss function $(L)$. The optimal (Jensen-McCallum) rule for that case can be obtained from the timeless perspective rule when eliminating the discount factor in the central-bank optimizing program, i.e., setting $\beta=1.0$. In practical terms, the Jensen-McCallum rule and the timeless perspective rule are very much alike because they differ only in the treatment of the central-bank discount factor. Thus, the (TR) according to the Jensen-McCallum criterion would be

$$
R_{t}=\mu_{1}^{\prime} R_{t-2}+\mu_{2}^{\prime} R_{t-1}+\mu_{3} E_{t-1} R_{t}+\mu_{4}^{\prime} E_{t} R_{t+1}+\mu_{5}^{\prime} E_{t} R_{t+2}+\mu_{6} \pi_{t}+\mu_{7}^{\prime} y_{t-1}+\mu_{8} y_{t}+\mu_{9}^{\prime} E_{t} y_{t+1},
$$

where $\mu_{1}^{\prime}=-\frac{\left(1-\phi_{0}\right)\left(1-\theta_{0}\right)}{1+\phi_{0}\left(1-\theta_{0}\right)}, \mu_{2}^{\prime}=\frac{\phi_{1} \theta_{1}+\left(1-\phi_{0}\right)+\left(1-\theta_{0}\right)}{1+\phi_{0}\left(1-\theta_{0}\right)}, \mu_{4}^{\prime}=\frac{\phi_{0}+\theta_{0}}{1+\phi_{0}\left(1-\theta_{0}\right)}, \mu_{5}^{\prime}=-\frac{\phi_{0} \theta_{0}}{1+\phi_{0}\left(1-\theta_{0}\right)}$, $\mu_{7}^{\prime}=-\frac{\gamma_{y}\left(1-\phi_{0}\right) \theta_{1}}{\gamma_{R}\left(1+\phi_{0}\left(1-\theta_{0}\right)\right)}$, and $\mu_{9}^{\prime}=-\frac{\gamma_{y} \phi_{0} \theta_{1}}{\gamma_{R}\left(1+\phi_{0}\left(1-\theta_{0}\right)\right)}$.

The coefficients are very similar to the ones in (TR), although they are not exactly the same. The deviation between the performance of (TR) and (TR') is quantitatively very small. Taking the unconditional expectation of the loss function under the baseline calibration $(\beta=0.99)$, the loss value ratio is $L^{T R} / L^{T R^{\prime}}=1.0012$, which implies that the loss value with (TR) is only 0.12 percent higher than the loss function value with (TR'). For related issues on monetary policy optimality, see McCallum (2005). 
